\title{
Body Mass Index Greater Than or Equal to 23
}

National Cancer Institute

\section{Source}

National Cancer Institute. Body Mass Index Greater Than or Equal to 23. NCI Thesaurus.

Code C138935.

Indicates a body mass index measurement greater than or equal to 23 . 